\title{
A importância da lei geral da micro e pequena empresa para o desenvolvimento dos pequenos empreendimentos, o caso do município de Miranda, MS
}

\author{
The importance of the general law of micro and small enterprise development of \\ small enterprises, the case of the municipality of Miranda, MS

\section{La importancia de la ley general de la micro y pequeña empresa de desarrollo de las pequeñas, el caso del municipio de Miranda, MS}

\section{L'importance de la loi generale de micro et petites entreprises" pour le developpement des petites entreprises, la cause de la municipalité de Miranda, MS}

\author{
Milton Cesar Pereira de Oliveira* \\ (milton.oliveira@ms.sebrae.com.br)
}

Recebido em 06/06/2013; revisado e aprovado em 17/09/2013; aceito em 11/08/2013

\begin{abstract}
Resumo: O presente artigo registra o trabalho desenvolvido pelo Serviço de Apoio às Micro e Pequenas Empresas (SEBRAE) para implementar a lei geral municipal das micro e pequenas empresas nos municípios brasileiros. O propósito do artigo é apresentar as mudanças significativas que foram surgindo após a aprovação da Lei Complementar 123/2006, desburocratizando a abertura e o fechamento de empreendimentos, simplificando tributos, facilitando o acesso a créditos e estimulando a exportação. O município de Miranda foi utilizado como base de estudo e pesquisa.
\end{abstract}

Palavras-chave: Lei Geral. Micro e pequenas empresas. Municípios.

Abstract: This article records the work of the support service for micro and small enterprises (SEBRAE) to implement the general municipal law of micro and small enterprises in the municipalities. The purpose of the article is to present the significant changes that have arisen after the adoption of the supplementary Law 123/2006, could ease the opening and closing of projects, simplifying taxes, facilitating access to credit and stimulating exports. The municipality of Miranda was used as a basis for study and research

Key words: General Law. Micro and small enterprises. Municipalities.

Resumen: Este artículo recoge el trabajo del Serviço de Apoio às Micro e Pequenas Empresas (SEBRAE) para implementar la ley municipal general de las micro y pequeñas empresas en los municipios. El propósito de este artículo es presentar los cambios significativos que han surgido después de la adopción de la Ley Complementaria 123/2006, podría facilitar la apertura y cierre de los proyectos, la simplificación de los impuestos, facilitando el acceso al crédito y estimular las exportaciones. El municipio de Miranda fue utilizado como base para el estudio y la investigación. Palabras clave: ley general. Micro y pequeñas empresas. Municipios.

Résumé: Cet article enregistre le travail du Serviço de Apoio às Micro e Pequenas Empresas (SEBRAE) pour mettre en œuvre le législation municipal général de micro et petites entreprises dans les municipalités. Le but de cet article est de présenter les modifications importantes qui ont surgi après l'adoption de la loi complémentaire 123/2006, pourrait faciliter l'ouverture et la fermeture des entreprises, la simplification des impôts, en facilitant l'accès au crédit et à stimuler les exportations. La municipalité de Miranda a été utilisé comme une base pour l'étude et la recherche. Mots-clés: loi générale. Micro et petites entreprises. Les municipalités.

\section{Introdução}

O tema principal do presente artigo é tratar a importância da criação da lei geral das micro e pequenas empresas para as cidades brasileiras, em especial do município de Miranda, MS. A oportunidade de estudar surgiu da relevância para o desenvolvimento econômico e sustentável dos municípios. Justifica-se a escolha por se tratar de assunto ainda pouco explorado no meio acadêmico, mas que tem muito a contribuir com a política pública municipal. Será utilizada como base de pesquisa a experiência acumulada de cinco anos junto a dados e ferramentas do Serviço Brasileiro de Apoio às Micro e Pequenas Empresas (SEBRAE).

O presente artigo tem por objetivo apresentar dados relevantes que possam estimular outros municípios a regulamentar a lei geral municipal das micro e pequenas empresas e, dessa forma, estimular o crescimento e o desenvolvimento da economia local.

A metodologia utilizada foi a pesquisa exploratória que se mostrou essencial para a realização do trabalho. Diante das

\footnotetext{
* Universidade Federal de Mato Grosso do Sul (UFMS), Campo Grande, MS, Brasil.
} 
informações obtidas, realizou-se um estudo bibliográfico, que demonstrou a disponibilidade de relatórios de gestão e pesquisas de mensuração, evidenciando os resultados efetivos alcançados após a aprovação da lei complementar 123/2006.

O artigo está organizado em cinco seções distintas, a saber: Micro e pequenas empresas; A lei complementar 123/2006 - Lei Geral das Micro e Pequenas Empresas; Mato Grosso do Sul e a sua Lei Geral; A Importância da lei Geral para o Município de Miranda e Considerações Finais.

Para refletir sobre essas questões o artigo proposto terá que responder o seguinte problema de pesquisa: quais foram os benefícios aos municípios após a criação da lei geral das micro e pequenas empresas?

\section{Micro e pequenas empresas}

Os tópicos abordados nesta seção introduzem o assunto para a formação da base conceitual empregada no artigo.

\subsection{Conceito}

Atualmente, no Brasil, a definição de microempresa e empresa de pequeno porte é feita pelo Art. 3ํ da Lei Complementar 123/2006,

Art. $3^{\circ}$ - Para efeitos desta Lei Complementar, consideram-se microempresas ou empresas de pequeno porte a sociedade empresária, a sociedade simples e o empresário a que se refere o art. 966 da Lei $\mathrm{n}^{\circ} 10.406$, de 10 de janeiro de 2002, devidamente registrados no Registro de Empresas Mercantis ou no Registro Civil de Pessoas Jurídicas, conforme o caso,

desde que:

1. No caso das microempresas, o empresário, a pessoa jurídica, ou a ela equiparada, aufira, em cada ano-calendário, receita bruta igual ou inferior a R \$360.000,00 (trezentos e sessenta mil reais);

2. No caso das empresas de pequeno porte, o empresário, a pessoa jurídica, ou a ela equiparada, aufira, em cada ano-calendário, receita bruta superior a $R \$ 360.000,00$ (trezentos e sessenta mil reais) e igual ou inferior a R\$ 3.600.000,00 (três milhões e seiscentos mil reais).
Outro critério utilizado para dimensionar as micro e pequenas empresas, baseiase no número de funcionários, que varia segundo diferentes autores. Na indústria, as microempresas possuem menos de vinte funcionários e as pequenas empresas podem chegar a até noventa e nove colaboradores. Já no comércio e nos serviços esses limites são de até nove funcionários nas microempresas e até quarenta e nove funcionários nas pequenas empresas (SEBRAE apud DOLABELA, 2002).

De acordo com o estudo sobre "As Micro e Pequenas Empresas Comerciais e de Serviço no Brasil 2001 (2003)", são características das MPEs:

- Baixa intensidade de capital;

- Altas taxas de natalidade e de mortalidade: demografia elevada;

- Forte presença de proprietários, sócios e membros da família como mão de obra ocupada nos negócios;

- Poder decisório centralizado;

- Estreito vínculo entre os proprietários e as empresas, não se distinguindo, principalmente em termos contábeis e financeiros, pessoa física e jurídica;

- Registros contábeis pouco adequados;

- Contratação direta de mão de obra;

- Utilização de mão de obra não qualificada ou semiqualificada;

- Baixo investimento em inovação tecnológica;

- Maior dificuldade de acesso ao financiamento de capital de giro; e

- Relação de complementaridade e subordinação com as empresas de grande porte.

\subsection{Da representatividade}

Conforme o "Manual de Desenvolvimento Dos Municípios (2011)", atualmente as MPEs representam 99,1\% das empresas urbanas, $85 \%$ dos estabelecimentos rurais do país, $25 \%$ do Produto Interno Bruto, gerando 14 milhões de empregos, o que significa $60 \%$ do emprego formal no país, respondendo, ainda, por $99,8 \%$ das empresas que são criadas a cada ano.

Segundo a RAIS (Relação Anual de Informações Sociais), entre 2000 e 2010, o número de empresas no Brasil cresceu $47 \%$, alcançando 6,1 milhões de negócios. Na mais recente avaliação do Banco Mundial, o Brasil cria 316000 novos negócios por ano, permanecendo em terceiro lugar como o país mais empreendedor do mundo. 


\begin{tabular}{|c|c|c|c|}
\hline Informações sobre MPE & Ano do dado & Brasil & Fonte \\
\hline \multicolumn{4}{|l|}{ Quantitativo de MPEs } \\
\hline Número de Micro e Pequenas Empresas registradas na RAIS & 2010 & 6.120 .927 & RAIS \\
\hline Número de optantes do Simples Nacional (em 27/01/2012) & 2012 & 5.940 .606 & SRF \\
\hline Número de empreendedores individuais (em 27/01/2012) & 2012 & 1.865 .497 & SRF \\
\hline \multicolumn{4}{|l|}{ Mercado de trabalho } \\
\hline Número de empregadores no Brasil & 2009 & 3.991 .512 & IBGE \\
\hline Número de empregados c/ carteira assinada em MPE & 2010 & 14.710 .631 & RAIS \\
\hline $\begin{array}{l}\text { Rendimento médio mensal dos empregadores no Brasil (em } \\
\text { salário mínimo) }\end{array}$ & 2009 & 6,7 & IBGE \\
\hline $\begin{array}{l}\text { Rendimento médio mensal dos empregados c/ carteira no } \\
\text { Brasil (em salário mínimo) }\end{array}$ & 2009 & 2,1 & IBGE \\
\hline $\begin{array}{l}\text { Rendimento médio mensal dos empregados c/ carteira nas } \\
\text { MPE (em R\$) }\end{array}$ & 2010 & $\mathrm{R} \$ 1.099$ & RAIS \\
\hline Massa de salários paga por MPE (em R $\$$ bilhões) & 2010 & $\mathrm{R} \$ 16,1$ & RAIS \\
\hline \multicolumn{4}{|l|}{ Comércio exterior } \\
\hline Número de MPEs exportadoras & 2010 & 11.858 & Funcex \\
\hline Valor total das exportações de MPEs (US\$ bilhões FOB) & 2010 & US\$2,0 bi & Funcex \\
\hline Valor médio exportado por MPE (US\$ mil FOB) & 2010 & US\$ 170,9 mil & Funcex \\
\hline
\end{tabular}

Fonte: SEBRAE (2012) - boletim estudos e pesquisas

\subsection{Da importância da lei para economia do município}

Segundo a Confederação Nacional de Municípios (CNM, 2011), as micro e pequenas empresas são importante para o desenvolvimento social e econômico dos municípios, pois na maioria das cidades brasileiras os pequenos negócios das áreas urbanas e rurais representam de $99 \%$ a $100 \%$ das atividades empresariais neles desenvolvidas. Esses comércios, de uma forma ou de outra, fortalecem a economia local, geram empregos e melhora a distribuição de renda, o que também contribui para a arrecadação de impostos e, consequentemente, futuras ações de investimentos no bem-estar-social e na qualidade de vida dos munícipes.

\section{A Lei Complementar 123/2006 - Lei Geral das Micro e Pequenas Empresas}

Nesta seção realizar-se-á uma breve exposição histórica dos aspectos relacionados à criação da lei geral das micro e pequenas empresas.

\subsection{Um breve histórico}

A Lei Geral das Microempresas e Empresas de Pequeno Porte (MPEs), insti- tuída pela Lei Complementar n. 123, de 14 de dezembro de 2006, surgiu da percepção das entidades representativas e de apoio às pequenas empresas, conjuntamente com o Congresso Nacional brasileiro, que, por sua vez, entenderam que a burocracia estava se tornando um dos principais entraves para o crescimento econômico do país, haja vista que o excesso de formalidades dificultava o funcionamento empresarial e propiciava uma redução na competitividade do mercado, além de incentivar a informalidade, principalmente no universo das micro e pequenas empresas. Outra questão burocrática então existente era o excesso de custos para as empresas e governos, custos esses que, é bom lembrar, refletiam diretamente no bolso da sociedade brasileira.

Diante desses fatos, o governo federal, por meio da lei complementar n. 123/2006, estabeleceu que à administração pública (federal, estadual e municipal) cumpre instituir normas gerais relativas ao tratamento diferenciado às MPEs, desburocratizando e facilitando a abertura, fechamento e alteração cadastral dos pequenos empreendimentos empresariais.

Após a aprovação e promulgação da referida lei, conforme levantamento do Departamento Intersindical de Estatística e Estudos Socioeconômicos (DIEESE, 2011), o Brasil vem observando ano a ano um crescimento 
significativo de sua economia e significativa diminuição da informalidade.

Para os empresários, como se sabe, ficou mais fácil pagar os impostos, obter créditos, ter acesso à tecnologia, vender para o poder público e até mesmo exportar. Outra questão que merece destaque, foi a criação, por aquela lei, da figura do Micro empreendedor individual (MEI), objetivando trazer para a formalidade, o que vem ocorrendo como esperado, trabalhadores que atuam por conta própria.

O MEI contempla os profissionais com faturamento de, no máximo, $\mathrm{R} \$ 60$ mil reais por ano e que possuem até um empregado contratado com salário mínimo ou piso da categoria, sendo que o seu custo mensal varia entre $R \$$ 32,10 e R $\$ 37,10$. Esses valores proporcionamlhes alguns benefícios, entre eles, auxílio maternidade, auxílio doença e aposentadoria.

Conforme a Lei n. 123/2006 seguem os benefícios previstos após sua aprovação:

1. Regime unificado de a puração e recolhimento dos impostos e contribuições da União, dos estados, do Distrito Federal e dos municípios, inclusive com simplificação das obrigações fiscais acessórias;

2. Desoneração tributária das receitas de exportação e substituição tributária;

3. Dispensa do cumprimento de certas obrigações trabalhistas e previdenciárias;

4. Simplificação do processo de abertura, alteração e encerramento das MPEs;

5. Facilitação do acesso ao crédito e ao mercado;

6. Preferência nas compras públicas;

7. Estímulo à inovação tecnológica;

8. Incentivo ao associativismo na formação de consórcios para fomentação de negócios;

9. Incentivo à formação de consórcios para acesso a serviços de segurança e medicina do trabalho;

10. Regulamentação da figura do pequeno empresário, criando condições para sua formalização;

11. Parcelamento de dívidas tributárias para adesão ao Simples Nacional.

2.2 Da importância para os municípios aderirem à lei

A partir da Lei Complementar n. 123/2006, compete aos municípios criarem mecanismos jurídicos para ajudar as micro e pequenas empresas no seu desenvolvimento, a elas assegurando "o pronto e imediato tratamento jurídico diferenciado", consoante estabelecido no seu artigo e parágrafo a seguir reproduzidos:

Art. 77. Promulgada esta Lei Complementar, o Comitê Gestor expedirá, em 6 (seis) meses, as instruções que se fizerem necessárias à sua execução.

$\S 1$ o O Ministério do Trabalho e Emprego, a Secretaria da Receita Federal, a Secretaria da Receita Previdenciária, os Estados, o Distrito Federal e os Municípios deverão editar, em 1 (um) ano, as leis e demais atos necessários para assegurar o pronto e imediato tratamento jurídico diferenciado, simplificado e favorecido às microempresas e às empresas de pequeno porte.

Conforme estudos realizados pelo SEBRAE (2011), as micro e pequenas empresas têm grande representatividade nos municípios brasileiros, pois os números mostram que para cada 100 empregos gerados no Brasil as micro e pequenas empresas são responsáveis por 67. O país ainda esbarra no problema da distribuição de renda, tanto que hoje os 10\% mais ricos detêm $46,9 \%$ da renda nacional, enquanto os $10 \%$ mais pobres se mantêm com apenas $0,7 \%$. O Banco Mundial por meio da pesquisa Doing Business (fazendo negócios), apresentou números de 183 países quanto à facilidade de empreender e nela consta 0 Brasil na $126^{a}$ posição.

Nessa mesma pesquisa são apontados os fatores que dificultam empreender no Brasil, quais sejam:

- Pagar impostos no Brasil consome 2.600 horas da vida de uma empresa e $67 \%$ do lucro;

- Fechar uma empresa insolvente demora 4 anos e custa $12 \%$ do patrimônio da empresa;

- Um alvará de construção demora 469 dias e são precisos 17 procedimentos;

- Exportar toma 13 dias e Importar 17 dias;

- Abrir uma empresa no Brasil depende de 13 procedimentos e demora em média 119 dias.

Esses entraves burocráticos, que haverão de ser removidos, são facilmente perceptíveis, sobretudo pelos gestores públicos municipais, que estão em contato o tempo todo com a realidade local, até porque em seus postos, eles possuem uma visão ampla acerca da impor- 
tância dos empreendedores no cotidiano das cidades, como sendo os responsáveis pelo fornecimento de boa parte dos serviços e produtos consumidos pela população e pela maioria dos empregos gerados na comunidade.

Conforme o guia do prefeito empreendedor (SEBRAE, 2007), para que os municípios possam transformar a lei em realidade eles precisam seguir cinco passos indispensáveis:

1. Decreto que defina as atividades de alto risco. Isso servirá para conceder às demais atividades o alvará de funcionamento Provisório e dispensa de vistoria prévia, com a finalidade de funcionamento imediato;

2. Decreto que regulamente o critério da fiscalização orientadora por meio de dupla visita. Em todas as constatações de irregularidades que não sejam de alto risco para os consumidores e para os trabalhadores, os fiscais da prefeitura, antes de multar, vão orientar e acertar prazo para a solução do problema;

3. Convênio com a secretaria estadual da fazenda e a junta comercial, visando estabelecer que a empresa instalada no município trabalhe com um único número de identificação fiscal e um único local para dar entrada em documentos;

4. Legislação ou decreto que estimule as compras públicas junto às MPEs locais;

5. Lei Geral Municipal, aprovada pela câmara dos vereadores e sancionada pelo prefeito, deverá regulamentar os vários dispositivos da Lei Geral.

É por esse e outros motivos que o SEBRAE desenvolve trabalho árduo e persistente voltado a estimular os gestores públicos municipais para apoiarem à implantação da Lei Geral das Micro e Pequenas Empresas nos municípios.

\section{Mato Grosso do Sul e a Lei Complemen- $\operatorname{tar} 123 / 2006$}

A seção apresenta o envolvimento do estado com o tema e números que comprovam sua importância.

\subsection{Breve histórico}

Dois anos depois da aprovação da lei geral, o Estado de Mato Grosso do Sul entendendo sua importância, em 30 de dezembro de 2008 aprovou o decreto de $n^{\circ} 12.683$, dis- pondo sobre tratamento diferenciado e simplificado a ser dispensado às microempresas e empresas de pequeno porte nas aquisições realizadas por órgãos e entes do estado, assim estatuindo:

Art. $2^{\circ}$ Para os efeitos deste Decreto, consideram-se microempresa ou empresa de pequeno porte a sociedade empresária, a sociedade simples e o empresário a que se refere o art. 966 da Lei Federal ${ }^{\circ}{ }^{10.406}$, de 10 de janeiro de 2002, devidamente registrados no Registro de Empresas Mercantis ou no Registro Civil de Pessoas Jurídicas, conforme o caso, desde que:

I - no caso das microempresas, o empresário, a pessoa jurídica, ou a ela equiparada, aufira, em cada ano-calendário, receita bruta igual ou inferior a $\mathrm{R} \$ 240.000,00$ (duzentos e quarenta mil reais);

II - no caso das empresas de pequeno porte, o empresário, a pessoa jurídica, ou a ela equiparada, aufira, em cada ano-calendário, receita bruta superior a $\mathrm{R} \$ 240.000,00$ (duzentos e quarenta mil reais) e igual ou inferior a $\mathrm{R} \$ 1.800 .000,00$ (um milhão e oitocentos mil reais).

Após esse decreto, o governo do estado, em parceria com o SEBRAE, vem contatando cada um dos municípios e explicando para os gestores públicos a importância da lei para o desenvolvimento da economia local. Dessa forma, surge no final de 2010 e início de 2011, o Projeto PROLOCAL, cujo escopo é contribuir para o desenvolvimento econômico e sustentável das cidades, promovendo o desenvolvimento territorial por meio do empreendedorismo legal. O projeto propõe ações voltadas ao crescimento das micro e pequenas empresas, aumentando suas possibilidades e a participação no mercado.

O PROLOCAL oferece a oportunidade para que os empreendedores conheçam a Lei Geral das Micro e Pequenas Empresas, formalizem suas atividades, aumentem as possibilidades de comercialização dos seus produtos e serviços, gerem empregos e rendas e, consequentemente, contribuam para a qualidade de vida dos seus municípios.

Hoje, no Estado de Mato Grosso do Sul, que conta com 78 municípios, 69 (88\%) deles já sancionaram a lei geral municipal, e a meta do SEBRAE e do governo estadual é atingir o total de $100 \%$ dos municípios até o final de 2014. 


\subsection{Indicadores econômicos das MPE no Mato Grosso do Sul}

\begin{tabular}{|lcc|}
\hline Indicador & Valor & Unidade de Medida \\
\hline Número de MPE & 69.945 & Quantidade \\
\hline Número de MPE - Comércio & 39.559 & Quantidade \\
\hline Número de MPE - Serviço & 21.111 & Quantidade \\
\hline Número de MPE - Indústria e Construção Civil & 9.275 & Quantidade \\
\hline Número de Empreendimentos Rurais & 41.104 & Quantidade \\
\hline Número de MPE com Empregados & 27.060 & Quantidade \\
\hline Número de Empregados com Carteira Assinada & 173.733 & Quantidade \\
\hline Número de Empreendimentos Informais & 131.903 & Quantidade \\
\hline Número de MPE Exportadoras & 64 & Quantidade \\
\hline Valor Exportado pelas MPE & 12,09 & US\$ milhões \\
\hline Taxa de Sobrevivência das MPE (após 2 anos) & 66,7 & Taxa \\
\hline Número de MPE Optantes pelo Simples & 80.933 & Quantidade \\
\hline Número de Empreendedores Individuais & 41.010 & Quantidade \\
\hline Saldo de Empresas Registradas & 5.505 & Quantidade \\
\hline Compras Governamentais das MPE & 300,01 & R\$ milhões \\
\hline Percentual das Compras Governamentais das MPE & 35,9 & Percentual \\
\hline
\end{tabular}

Fonte: site MPE Data (2012).

Dos dados acima apresentados, verificou-se que em nosso estado existe um numero muito expressivo de empreendimentos informais, motivo pelo qual o governo, em conjunto com os municípios, deve buscar políticas publicas voltada a estimular a formalização desses negócios, uma empresa informal desencadeia uma série de problemas, entre eles estão: o não recolhimento de impostos, empregados sem carteira assinada, produtos e serviços sem procedência. Com implementação da lei geral nos municípios o estado pretende diminuir significamente o numero das empresas informais no Mato Grosso do Sul.

\section{Da importancia da lei geral para o mini- cípio de Miranda}

A seção apresenta o envolvimento, adesão e os benefícios do Município de Miranda junto à lei geral das Micro e Pequenas Empresas.

\subsection{Miranda e suas características}

O município de Miranda localiza-se ao oeste do Estado de Mato Grosso do Sul. Sua área é de $5.478,836 \mathrm{Km}^{2}$. A sede do município fica distante da capital, Campo Grande,
$194 \mathrm{~km}$ e $1228 \mathrm{~km}$ da capital federal. Suas principais atividades econômicas são: a agropecuária, indústrias de cerâmica, turismo de pesca e ecoturismo.

O município está sob a influência da bacia do rio da Prata e seus principais rios são: o rio Aquidauana, afluente pela margem direita do rio Miranda, com $620 \mathrm{~km}$ de extensão, e o rio Salobra, afluente pela margem esquerda. Sua vegetação predominante é formada por cerrado e o pantanal. Segundo censo do (IBGE 2010) a população de Miranda é de 25.595 mil habitantes, sendo 13.221 homens e 12.374 mulheres.

4.2 Miranda e a lei geral das micro e pequenas empresas

Após a aprovação da lei geral no âmbito federal, ficou a cargo de cada município a implementação do processo voltado a garantir condições especiais com o intuito de estimular o empreendedorismo local. A partir desse momento os quadros técnico, jurídico e político da cidade começaram a estudar e debater junto à população os pontos importantes e que são de autonomia municipal.

Segundo a Lei Complementar $\mathrm{n}$. 123/2006, algumas regras nela estabelecida 
são de aplicação automática e, portanto, não necessitam de regulamentação municipal e são aplicadas em todo o território nacional.

Por outro lado, existem normas que exigem regulamentação por parte do município, como, por exemplo, o art. 48, inciso I, que cuida da licitação exclusiva para a MPE nas contratações até $\mathrm{R} \$ 80.000,00$ (oitenta mil reais). Outros artigos da lei que exigem regulamentação por parte dos municípios são: $4^{\circ}$, $5^{\circ}, 47^{\circ}, 55^{\circ}, 79^{\circ}$, e $85^{\circ}$. Além dessas normas, pode o município incluir outras, respeitando sua competência legislativa, outorgada pela Constituição Federal, sobre temas que tratam de incentivos:

- Associativismo

- Incentivo a Inovação

- Crédito

- Turismo

- Pequeno produtor Rural

- Educação Empreendedora

Em 16 de novembro de 2010, o município de Miranda aprovou a lei complementar n. 029/2010, beneficiando, assim, os pequenos empreendimentos locais:

Artigo $1^{0}$ - Esta Lei regula o tratamento jurídico diferenciado, simplificado e favorecido assegurado ao microempreendedor individual (MEI), às microempresas (ME) e empresas de pequeno porte (EPP), doravante simplesmente denominadas MEI, ME e EPP, em conformidade com o que dispõe os arts. 146, III, d, 170, IX, e 179 da Constituição Federal e a Lei Complementar Federal ${ }^{\circ}$ 123/06, criando a LEI GERAL MUNICIPAL DA MICROEMPRESA E EMPRESA DE PEQUENO PORTE DE MIRANDA/MS.

Parágrafo Único - Aplicam-se ao Microempreendedor Individual - MEI todos os benefícios e todas as prerrogativas previstas nesta Lei para as ME e EPP.
Artigo $2^{\circ}$ - O tratamento diferenciado, simplificado, favorecido e de incentivo às microempresas, às empresas de pequeno porte e ao microempreendedor individual incluirá, entre outras ações dos órgãos e entes da administração municipal:

I - os incentivos fiscais;

II - o incentivo à formalização de empreendimentos;

III - a unicidade e a simplificação do processo de registro e de legalização de

empresários e de pessoas jurídicas;

IV - a simplificação, racionalização e uniformização dos requisitos de segurança

sanitária, metrologia, controle ambiental e prevenção contra incêndios, para os fins de registro, legalização e funcionamento de empresários e pessoas jurídicas,

inclusive com a definição das atividades consideradas de alto risco;

$\mathrm{V}$ - a preferência nas aquisições de bens e serviços pelos órgãos públicos municipais.

Essa lei está em consonância com o artigo 77 da LC n. 123/2006, autorizando os municípios e os demais entes da Federação, no limite de suas competências, a editarem as leis e os demais atos necessários para assegurar o tratamento jurídico diferenciado, simplificado e favorecido às MPEs.

\subsection{Beneficios gerados após implementação} da lei geral em Miranda

Com a aprovação da lei geral municipal, consoante o resultado da consulta realizada no final de maio de 2012, junto aos dados do portal do empreendedor, o município de Miranda ganhou 238 novos micro empreendedores individuais, divididos nas seguintes formas de atividades:

\begin{tabular}{|c|c|c|}
\hline Forma Atuação & n. MEI & $\%$ \\
\hline Estabelecimento fixo & 165 & $69,33 \%$ \\
\hline Porta a Porta, postos móveis ou por ambulantes & 41 & $17,23 \%$ \\
\hline Em local fixo, fora da loja & 13 & $5,46 \%$ \\
\hline Internet & 08 & $3,36 \%$ \\
\hline Correios & 05 & $2,1 \%$ \\
\hline Televendas & 04 & $1,68 \%$ \\
\hline Máquinas automáticas & 02 & $0,84 \%$ \\
\hline
\end{tabular}

Fonte: Portal do empreendedor. 
De acordo com a Jucems (Junta Comercial do Estado de Mato Grosso do Sul, 2012), do ano de 2010 até um mês antes da aprovação da lei municipal, Miranda contava com 758 empresas ativas. Após 16 meses, com a lei implantada, o município saltou para o expressivo número de 841 empresas e, com isso, a cidade ganhou 83 novos empreendimentos em um curto período de tempo, gerando empregos e renda.

Atualmente, o município possui outros 321 novos negócios formalizados, e os dados demonstram a importância de debater políticas públicas locais, a fim de beneficiar diretamente os munícipes e gerar dividendos para o poder público.

\section{Considerações finais}

Neste artigo buscou-se investigar a importância da implantação da lei geral municipal nas micro e pequenas empresas. Ao regulamentá-la, o administrador público assegura melhores condições para os empresários locais, promovendo a competitividade, a redução da informalidade, o incentivo para a inovação tecnológica, bem como o aumento de empregos e renda, beneficiando toda a sociedade.

A Lei Complementar n. 123/2006 obteve outros avanços importantes no setor. Entre eles, a criação da rede nacional para a simplificação do registro e da legalização de empresas e negócios - REDESIM, que tem como propósito facilitar as aberturas, alterações e baixas de empresas em todo país.

Após as pesquisas ficou evidente que os municípios que aderiram à lei obtiveram ganhos em suas receitas e melhoraram a qualidade de vida entre seus munícipes. $\mathrm{O}$ município de Miranda, especificamente, não foi diferente. Desde a sua promulgação da lei recebeu 321 novas empresas, o que por sua vez, estimulou a economia local, gerando maiores empregos e aumentou a arrecadação municipal.

Portanto, é de se concluir que a lei geral das micro e pequenas empresas é uma ferramenta de desenvolvimento para os municípios, consubstanciada em política pública eficiente, consistente e sustentável, que deve servir de estímulo aos empreendedores e aos gestores púbicos, bem como atuar como base para outras políticas de incentivo ao crescimento dos municípios.

\section{Referências}

BRASIL TEM. Relação anual de informações sociais (RAIS): microdados. Brasília, 2000-2010. CD ROM.

CADASTRO CENTRAL DE EMPRESAS (CEMPRE). Disponível em: <http://www.ibge.gov.br/home/ estatistica/economia/cadastroempresa/2010/default. shtm>. Acesso em: 25 maio 2012 .

CONFEDERAÇÃO NACIONAL DE MUNICÍPIOS (CNM). Disponível em: <http://www.cnm.org.br>. Acesso em: 17 maio 2012.

CONFEDERAÇÃO NACIONAL DE MUNICÍPIOS (CNM); SERVIÇO BRASILEIRO DE APOIO ÀS MICRO E PEQUENAS EMPRESAS (SEBRAE). Manual de Desenvolvimento dos municípios. Brasília: CNM/SEBRAE, 2011. 104p. (v. 1).

DECRETO n. 12683, de 30/12/08. Simples Nacional. Disponível em: <http://www.sebrae.com.br/customizado/lei-geral/regulamentacao-da-lei-geral-nosestados/estados/mato-grosso-do-sul/Decreto_Estadual_Lei_Geral.pdf>. Acesso em: 13 maio 2012.

DOING BUSINESS. Medindo regulamentações de negócios. Disponível em: <http://www.doingbusiness. org/data/exploreeconomies/brazil>. Acesso em: 26 maio 2012.

DOLABELA, Fernando. O segredo de Luísa. São Paulo: Cultura editores associados, 2002.

INSTITUTO BRASILEIRO DE GEOGRAFIA E ESTATÍSTICA (IBGE). Coordenação de Serviços e Comércio. As Micro e pequenas empresas comerciais e de serviços no Brasil: 2001. Estudos e pesquisas. Informação econômica, Rio de Janeiro, n. 1, 2003.

Disponível em: <http://www.ibge.gov.br>. Acesso em: 15 maio 2012.

JUNTA COMERCIAL DO ESTADO DE MATO GROSSO DO SUL (JUCEMS). Disponível em: <http:/ / www. jucems.ms.gov.br/templates/apresentacao/componentefixo/gerador/gerador.php?pag=1937\&template=21>. Acesso em: 27 maio 2012.

LEI COMPLEMENTAR N. 29, de 16 de novembro de 2010. Disponível em: <http://www.miranda.ms.gov. br/arquivos/LEI\% 20COMPLEMENTAR \% 2029\% 20- \% 202010\% 20LEI\% 20GERAL \% 20MUNICIPAL \% 20 DA \% 20ME, \% 20EPP\%20E\% 20MICROEMPREENDEDOR\%20INDIVIDUAL.pdf > . Acesso em: 25 maio 2012.

PORTAL DO EMPREENDEDOR. Disponível em: $<w w w$.portaldoempreendedor.gov.br/> . Acesso em: 12 maio 2012.

Lei Complementar 126/06 . Disponível em: <http:/ / www.portaldoempreendedor.gov.br/modulos/entenda/legislacao.php>. Acesso em: 21 fev. 2011. SERVIÇO BRASILEIRO DE APOIO ÀS MICRO E PEQUENAS EMPRESAS (SEBRAE). Anuário do trabalho na micro e pequena empresa: 2010-2011. 4. ed. Brasília, DF: DIEESE, 2011. 
A importância da Lei Geral da Micro e Pequena Empresa para o desenvolvimento dos pequenos empreendimentos, o caso do município de Miranda, MS

Guia do prefeito empreendedor: 2007/ SEBRAE. Coordenação da Unidade de Políticas Públicas. Brasília: SEBRAE, 2007. 56p.

. Disponível em: <http://www.sebrae.com.br/ atender/customizado/lei-geral>. Acesso em: 10 maio 2012.
VADE MERCUM. Obra coletiva de autoria da Editora Saraiva com a colaboração de Antonio Luiz de Toledo Pinto, Márcia Cristina Vaz dos Santos Windt e Lívia Céspedes. 11. ed. Atual. e ampl. São Paulo: Saraiva. 2011. 
